\title{
Point Mutations in the Stem-Loop at the 3' End of Mouse Histone mRNA Reduce Expression by Reducing the Efficiency of $3^{\prime}$ End Formation
}

\author{
NIRANJAN B. PANDEY,${ }^{1} \dagger$ ANTHONY S. WILLIAMS, ${ }^{1,2}$ JIAN-HUA SUN, ${ }^{1,2} \ddagger$ VIVETTE D. BROWN, ${ }^{1,2}$ \\ URSULA BOND, ${ }^{3} \S$ AND WILLIAM F. MARZLUFF ${ }^{1,2,4 *}$
}

Institute of Molecular Biophysics ${ }^{1}$ and Department of Chemistry, ${ }^{4}$ Florida State University, Tallahassee, Florida 32306;

Program in Molecular Biology and Biotechnology, University of North Carolina, Chapel Hill, North Carolina 27599²; and Howard Hughes Medical Institute, Department of Biochemistry and Biophysics, Yale University

School of Medicine, New Haven, Connecticut $06510^{3}$

Received 3 September 1993/Returned for modification 7 October 1993/Accepted 30 November 1993

\begin{abstract}
Mammalian histone mRNAs end in a highly conserved stem-loop structure, with a six-base stem and a four-base loop. We have examined the effect of mutating the stem-loop on the expression of the histone mRNA in vivo by introducing the mutated histone genes into $\mathrm{CHO}$ cells by stable transfection. Point mutations have been introduced into the loop sequence and into the UA base pair at the top of the stem. Changing either the first or the third base of the conserved UYUN sequence in the loop to a purine greatly reduced expression, while changing both U's to purines abolished expression. A number of alterations in the stem sequence, including reversing the stem sequence, reversing the two base pairs at the base of the stem, or destroying the UA base pair at the top of the stem, also abolished expression. Changing the UA base pair to a CG or a UG base pair also reduced expression. The loss of expression is due to inefficient processing of the pre-mRNA, as judged by the efficiency of processing in vitro. Addition of a polyadenylation site or the wild-type histone processing signal downstream of a mutant stem-loop resulted in rescuing the processing of the mutant pre-histone mRNA. These results suggest that if the histone pre-mRNA is not rapidly processed, then it is degraded.
\end{abstract}

The replication-dependent histone genes differ from other histone genes in that they lack intervening sequences and they encode mRNAs which are not polyadenylated (18). Instead, the histone mRNAs end in a highly conserved stem-loop structure, a six-base stem with a four-base loop (1). The $3^{\prime}$ end of mammalian histone mRNA is formed by an endonucleolytic cleavage which requires the stem-loop and a $3^{\prime}$ purine-rich region which interacts with U7 small nuclear RNA (snRNA) $(2,4,6,22)$. There are at least three components required for processing, the stem-loop-binding protein (SLBP), the U7 small nuclear ribonucleoprotein (snRNP), and a heat-labile factor $(7,16,19,33)$.

The stem-loop at the $3^{\prime}$ end of histone mRNA provides some of the functions of the poly(A) tail found in other mRNAs $(13,17)$. It is important in regulating the half-life of histone mRNA $(9,24)$ as well as in stimulating the export of histone mRNA from the nucleus $(5,32)$. While the stem-loop sequence is highly conserved among different histone genes, the U7 snRNP binding site varies widely among different histone genes (15). The differences in the U7 binding site result in different efficiencies of pre-mRNA processing, and this contributes to the relative expression of individual histone genes encoding the same histone protein (15).

\footnotetext{
${ }^{*}$ Corresponding author. Mailing address: Program in Molecular Biology and Biotechnology, 132 MBBRL, CB\# 7100, University of North Carolina, Chapel Hill, NC 27599. Phone: (919) 962-8920. Fax: (919) 966-6821.

$\dagger$ Present address: Department of Biochemistry and Molecular Biology, Harvard University, Cambridge, MA 02138.

$\ddagger$ Present address: Department of Plant Biology, The Scripps Research Institute, La Jolla, CA 92037.

$\S$ Present address: Biology Department, Fairfield University, Fairfield, CT 06430 .
}

The efficiency of histone pre-mRNA processing is also regulated during the cell cycle. In serum-starved fibroblasts (29) and in continuously cycling $\mathrm{CHO}$ cells (11), histone mRNA is poorly processed during $G_{1}$ phase and is then efficiently processed during $S$ phase. The increase in processing efficiency plays a major role in the rapid accumulation of histone mRNA at the start of $\mathrm{S}$ phase. Decreased processing efficiency is due to a lack of the heat-labile factor $(7,16)$ and may involve masking the $5^{\prime}$ end of the U7 snRNA to prevent it from base pairing with the histone mRNA (12).

We report here the effects of making small alterations in the conserved nucleotides of the stem-loop of the mouse histone H2a-614 gene. Changes in the third base of the loop or in the top base pair of the stem greatly reduced expression of histone mRNA. A similar reduction was found in the ability to process the same mutant pre-mRNAs in vitro. Addition of a polyadenylation site or a wild-type processing signal downstream of the mutant stem-loop resulted in rescuing the processing of the mutant pre-mRNA. These results suggest that if histone pre-mRNA is not rapidly processed, then the transcript is rapidly degraded, suggesting that there is a kinetic competition between productive processing and wastage of pre-mRNAs.

\section{MATERIALS AND METHODS}

Construction of altered histone genes. The mutations in the stem-loop sequences of the mouse histone $\mathrm{H} 2 \mathrm{a}-614$ gene were constructed by making double-stranded oligonucleotide cassettes which were introduced into the histone gene. This approach was necessary since introduction of site-specific mutants was unsuccessful, presumably because the oligonucleotide and/or the single-stranded template DNA assumes a stem-loop structure and hence prevents efficient priming of second-strand synthesis. The first set of oligonucleotides in- 


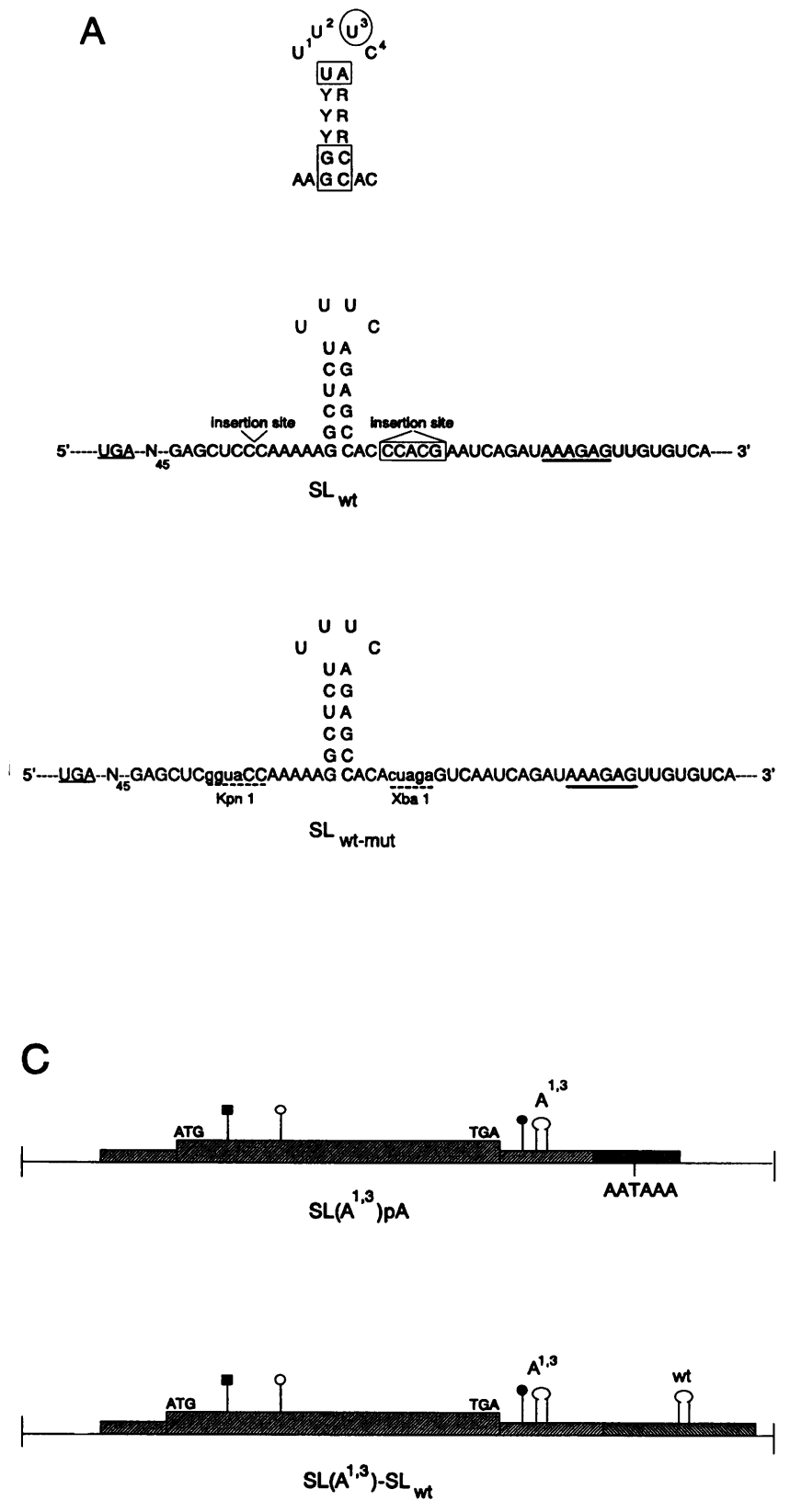

B

\begin{tabular}{|c|c|c|c|}
\hline $\begin{array}{c}U{ }^{U} U_{C} \\
U A \\
C G \\
U A \\
C G \\
C G \\
G C \\
A A G C A C\end{array}$ & $\begin{array}{c}U^{U}{ }^{a} C \\
U A \\
C G \\
U A \\
U A \\
C G \\
G C \\
A A G C A C\end{array}$ & $\begin{array}{c}{ }^{U}{ }^{G}{ }^{G} C \\
C G \\
U A \\
C G \\
\text { CG } \\
G C \\
A A G G C A C\end{array}$ & $\begin{array}{c}U^{U} U_{C} \\
{ }_{U A} \\
\text { CG } \\
U A \\
\text { CG } \\
\text { GC } \\
\text { AAGGCAC }\end{array}$ \\
\hline $\mathbf{S L}_{m}$ & $\operatorname{SL}\left(A^{1,3}\right)$ & $S L\left(G^{1,3}\right)$ & $S L\left(G^{1}\right)$ \\
\hline
\end{tabular}

\begin{tabular}{|c|c|c|c|}
\hline $\begin{array}{c}U{ }^{U}{ }^{g} C \\
U A \\
C G \\
U A \\
C G \\
G C \\
G G C \\
A M G C A C\end{array}$ & $\begin{array}{c}U^{U}{ }^{\mathbf{a}} \mathbf{C} \\
\text { UA } \\
C G \\
U A \\
\text { CG } \\
\text { GC } \\
\text { AAG CAC }\end{array}$ & $\begin{array}{c}U U_{C}^{U} \\
C \\
C g \\
C G \\
U A \\
C G \\
G C \\
C A G C\end{array}$ & $\begin{array}{c}U^{U}{ }^{U} \\
U_{g} \\
C G \\
U A \\
U^{\prime} G \\
\text { GG } \\
\text { GC } \\
\text { AAG CAC }\end{array}$ \\
\hline$\left.S L G^{3}\right)$ & $S L\left(A^{3}\right)$ & $S L(C G)$ & SL(UG) \\
\hline
\end{tabular}

\begin{tabular}{|c|c|c|c|}
\hline $\begin{array}{c}U U^{U} U^{U} \\
U C \\
U_{C} \\
C G \\
U A \\
C G \\
G C \\
G C \\
A A G C A C\end{array}$ & $\begin{array}{c}U^{U} U^{U} \\
{ }_{U} \mathbf{C} \\
C G \\
U A \\
U A \\
C G \\
G C \\
A A G C A C\end{array}$ & 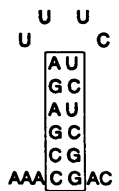 & $\begin{array}{c}U^{U} U^{U} \\
U A \\
C G \\
U A \\
C G \\
C G \\
C G \\
C G A C\end{array}$ \\
\hline SL(UC) & SL(UU) & SL(RS) & (CG/CG) \\
\hline
\end{tabular}

FIG. 1. Structures of the mutant histone genes. (A) Structure of the consensus sequence of the $3^{\prime}$ end of histone mRNA. The boxed nucleotides have been absolutely conserved among different metazoan histone mRNAs (17). The sequence of the $3^{\prime}$ end of the H2a-614 $\left(\mathrm{SL}_{\mathrm{wt}}\right)$ histone gene used in these studies is shown in the middle. At the bottom is the sequence of the $3^{\prime}$ end of the $\mathrm{SL}_{\mathrm{wt} \text {-mut }}$ gene, which has the same alterations flanking the stem-loop present in the mutant genes in panels B and C. The nucleotides in lowercase are the changes introduced. The KpnI site and the remnant of the $X b a \mathrm{I}$ site are indicated. The underlined nucleotides are the core of the U7 snRNP binding site. (B) Structures of the mutant stem-loop sequences analyzed. The altered nucleotides are shown in lowercase. SL(RS) has the entire stem reversed, and SL(CG/CG) has part of the stem reversed; the altered nucleotides in these genes are boxed. (C) Structures of genes containing two $3^{\prime}$ processing sites. The mouse $\beta$-globin poly(A) signal (top) or the normal histone $\mathrm{H} 2 \mathrm{a}-6143^{\prime}$ processing signal (bottom) was attached $3^{\prime}$ to the mutant gene. Positions of the restriction enzyme sites used in S1 nuclease mapping are indicated ( $\uparrow$, AvaI;, , NarI; $९$, SacI).

Introduction of genes into $\mathrm{CHO}$ cells. The histone genes

serted a $K p n I$ site $5^{\prime}$ of the stem-loop and an $X b a I$ site between the stem-loop and the U7 binding site. A second set of double-stranded oligonucleotides was synthesized with overhangs compatible with the $K p n I$ and $X b a I$ sites (they regenerated the $K p n I$ site but not the $X b a I$ site), and these contained the desired mutations in the stem-loop. The sequences of the mutants used in this study are shown in Fig. 1. The genes containing two processing signals were constructed by placing either the mouse $\beta$-globin polyadenylation signal or the wildtype histone processing signal 60 nucleotides (nt) $3^{\prime}$ of the end of $\operatorname{SL}\left(\mathrm{A}^{1,3}\right)$ mutant processing signal. The cassettes containing the wild-type histone H2a-614 $3^{\prime}$ end signal (23) or the mouse $\beta$-globin polyadenylation signal have been described previously (15). were introduced into $\mathrm{CHO}$ cells by cotransfection with the pSV2neo gene, using the Polybrene technique (3). Stable G418-resistant colonies were selected as previously described (14). Mass cultures were grown from 20 to 50 pooled colonies. Total cell RNA was prepared from exponentially growing (less than $50 \%$ confluent) $\mathrm{CHO}$ cells which had been fed fresh medium $16 \mathrm{~h}$ prior to isolation of the RNA. In some experiments, cells were treated with $5 \mathrm{mM}$ hydroxyurea or $5 \mu \mathrm{g}$ of actinomycin $\mathrm{D}$ per $\mathrm{ml}$ for $1 \mathrm{~h}$ prior to isolation of the RNA. In the experiment in Fig. 3D, cells were fractionated into nuclear, polysomal, and cytoplasmic fractions as previously described (26) prior to isolation of the RNA. RNA was isolated and analyzed in an S1 nuclease assay as previously described (10). 
The probes used were the $\mathrm{H} 2 \mathrm{a}-614$ gene or the mutant $\mathrm{H} 2 \mathrm{a}$ genes labeled at either the $3^{\prime}$ end of the $A v a$ I site at codon 20 or the $3^{\prime}$ or $5^{\prime}$ end of the NarI site at codon 43 . These probes detected the endogenous hamster $\mathrm{H} 2 \mathrm{a}$ mRNA as well as the mRNA from the transfected genes.

Processing of histone pre-mRNA in vitro. The PstI-toHindIII fragment extending from codon 83 in the coding region to $35 \mathrm{nt} 3^{\prime}$ of the $3^{\prime}$ end of the histone mRNA was cloned into pGEM3zf(+). A synthetic RNA labeled with $\left[\alpha-{ }^{32} \mathrm{PO}_{4}\right]$ UTP was synthesized by using T7 RNA polymerase. The probe was incubated with a $\mathrm{HeLa}$ cell nuclear extract exactly as previously described, and the products were analyzed by gel electrophoresis (2).

Binding of the stem-loop with nuclear proteins. Synthetic 30-nt RNAs containing the wild-type stem-loop sequence were synthesized from oligonucleotide templates by the method of Milligan et al. (20) as previously described (25). Mutant RNAs which were identical in sequence except for the stem-loop region were synthesized by using appropriate oligonucleotides. A nuclear extract was prepared from mouse myeloma cell nuclei by extraction with $0.6 \mathrm{M} \mathrm{KCl}$ as described previously (25). The binding of the RNA to the nuclear proteins and analysis by nondenaturing gel electrophoresis were carried out exactly as described previously (25).

\section{RESULTS}

The stem-loop structure at the $3^{\prime}$ end of histone mRNA has been highly conserved in metazoans (17). The consensus sequence for this structure is shown in Fig. 1A. The conserved features (boxed in Fig. 1A) include two G's followed by four pyrimidines on the $5^{\prime}$ stem, with the complementary four purines followed by two C's on the 3' side. The top base pair is always a UA base pair. The loop has a $U$ in the first position $>95 \%$ of the time and a $U$ in the third position $100 \%$ of the time. There is often a $U$ in the second position as well. The fourth base in the loop is variable. The stem-loop is usually preceded by at least two A residues and is followed by an AC. The U7 binding site is located 10 to 15 nt $3^{\prime}$ of the stem-loop, and both the distance and sequence of the U7 snRNP binding site vary among different murine histone genes (15). The core of the U7 binding site is a purine-rich AAAGAG sequence which base pairs with U7 snRNA (2).

The sequence of the $3^{\prime}$ end of the parent $\mathrm{H} 2 \mathrm{a}-614$ gene (referred to as $\mathrm{SL}_{\mathrm{wt}}$ ) is shown below the consensus stem-loop sequence. We have examined the effects of making alterations in the conserved first and third bases in the loop, in the conserved UA base pair at the top of the stem, and in the conserved CG base pairs at the base of the stem. To facilitate the construction of the mutant genes, we introduced a KpnI site before the stem-loop and an $X b a I$ site between the stem-loop and the $\mathrm{U} 7$ binding site and then replaced the wild-type stem loop with appropriate double-stranded oligonucleotides containing the desired mutations. As a control, we constructed the $\mathrm{SL}_{\mathrm{wt}-\mathrm{mut}}$ gene, which has the normal stem-loop sequence. The sequence of this gene is shown in Fig. 1A, showing the altered nucleotides before the stem-loop and between the stem-loop and the U7 snRNP binding site, regions which are highly variable among different murine histone genes (15). The $\mathrm{SL}_{\mathrm{wt}-\mathrm{mut}}$ gene is expressed identically to the wild-type gene (see Fig. 2).

Figure 1B shows the different mutations that we introduced into the stem-loop sequence, altering the conserved first or third bases of the loop or the conserved base pairs of the stem. These genes are named according to the bases in the loop which were changed or by the change in the base pairs. In addition, we also constructed a gene, SL(RS), in which the stem sequence was reversed but the loop sequence remained the same.

Two genes were constructed which had two potential processing signals (Fig. 1C). The mouse $\beta$-globin polyadenylation signal was placed about $100 \mathrm{nt} 3^{\prime}$ of the $\left(\mathrm{A}^{1,3}\right)$ mutant stem-loop to give the $\operatorname{SL}\left(\mathrm{A}^{1,3}\right) \mathrm{pA}$ gene. The wild-type histone H2a-614 $3^{\prime}$ processing signal was placed $81 \mathrm{nt} 3^{\prime}$ of the mutant $\left(\mathrm{A}^{1,3}\right)$ stem-loop to give the $\operatorname{SL}\left(\mathrm{A}^{1,3}\right)-\mathrm{SL}_{\mathrm{wt}}$ gene.

These genes were introduced into $\mathrm{CHO}$ cells in low copy number by stable transfection. The expression level of transfected mouse histone genes is very reproducible in this system, allowing comparison of the expression of different histone genes (14). The expression of the mRNAs was determined by an S1 nuclease assay which measures the level of the endogenous histone $\mathrm{H} 2 \mathrm{a}$ mRNA as well as the mRNA from the transfected gene. The relative expression of the mouse histone genes is determined by comparing the intensities of the protected fragment from the transfected gene with those of the endogenous hamster $\mathrm{H} 2 \mathrm{a}$ mRNAs. At least two independent pools of transfected cells (each containing at least 20 independent colonies) were analyzed for each construct.

In addition to assaying for the processed mRNAs from the transfected genes, we also could detect unprocessed mRNAs from the mutant genes by doing the same $\mathrm{S} 1$ nuclease assay using the wild-type H2a-614 gene as a probe. Since the sequence of the wild-type and mutant genes diverges $24 \mathrm{nt}$ from the end of the histone mRNA (Fig. 1A), any unprocessed (or processed) transcripts from the mutant genes will protect a 316-nt fragment when assayed with the wild-type histone H2a-614 gene labeled at the NarI site or a 392-nt fragment with use of the H2a-614 gene labeled at the $A v a I$ site. Thus, we can detect unprocessed transcripts from the mutant genes which did not express any mature mRNA, demonstrating that the genes had been successfully transfected into the cells.

Reversing the stem sequence abolishes expression in vivo. When the intact $\mathrm{H} 2 \mathrm{a}-614$ gene is transfected into $\mathrm{CHO}$ cells, it is expressed at high levels accounting for about $20 \%$ of the $\mathrm{H} 2 \mathrm{a}$ mRNA in the hamster cell (Fig. 2A, lane 1) (14). When the mutant linker sequences were introduced into the wild-type gene to give the $\mathrm{SL}_{\mathrm{wt} \text {-mut }}$ gene, expression was not affected (Fig. 2A, lane 4). The probe used in these experiments was derived from the $\mathrm{SL}_{\mathrm{wt}-\mathrm{mut}}$ gene and maps the transcripts from the H2a-614 gene to the KpnI site just prior to the stem-loop, where the two sequences are divergent (Fig. 1A), resulting in a protected fragment which is $24 \mathrm{nt}$ shorter than the fragment protected by the transcript from the $\mathrm{SL}_{\mathrm{wt}-\mathrm{mut}}$ gene. This demonstrates that the introduction of sequences flanking the stem-loop does not affect the expression of the H2a-614 mRNA. The changes in the sequence $5^{\prime}$ of the stem-loop are outside the conserved region, and we have previously shown that a fragment starting at the SacI site contains all the information necessary for efficient $3^{\prime}$ end formation in vivo (15, 23). The changes in the region between the stem-loop and the U7 binding site are not in a conserved region but alter the spacing between the stem-loop and the spacer element. However, they do not affect the processing efficiency of the H2a-614 gene either in vivo (Fig. 2A) or in vitro (see Fig. 6).

The transcripts from the $\mathrm{SL}_{\mathrm{wt}-\mathrm{mut}}$ gene also showed appropriate posttranscriptional regulation. When DNA synthesis is inhibited, there is a rapid reduction in the amount of histone mRNA (28). There was a similar reduction in the amount of the $\mathrm{SL}_{\mathrm{wt} \text {-mut }}$ mRNA when cells were treated with hydroxyurea (Fig. 2A, lanes 2 and 5).

Figure $2 \mathrm{~B}$ shows that when the stem sequence was reversed, there was no detectable expression of mRNAs ending at the $3^{\prime}$ 

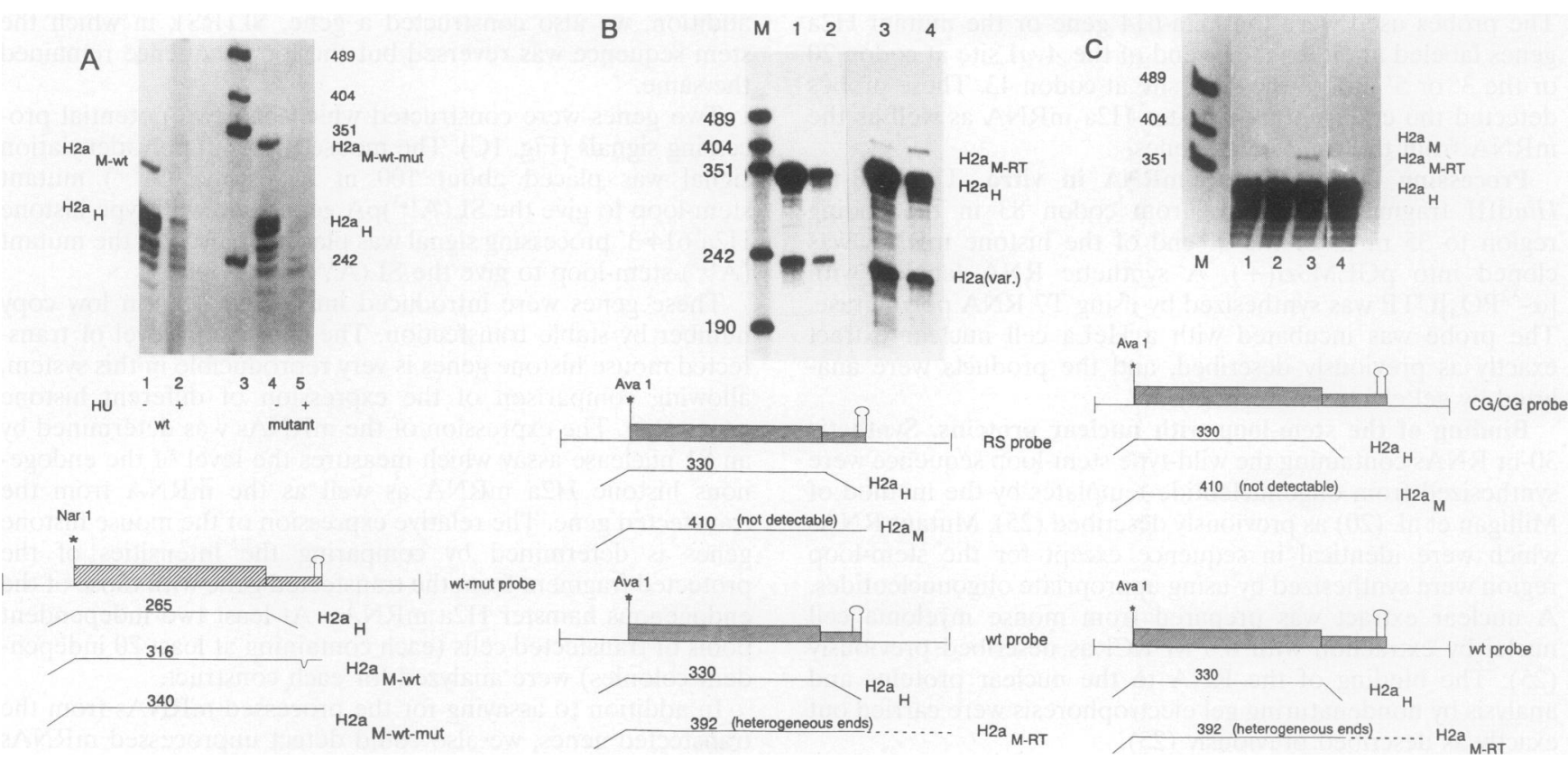

FIG. 2. Expression of the $\mathrm{SL}_{\mathrm{wt}-\mathrm{mut}}$ gene and the $\mathrm{SL}(\mathrm{RS})$ genes. (A) The $\mathrm{H} 2 \mathrm{a}-614$ gene and the $\mathrm{SL}_{\mathrm{wt}-\mathrm{mut}}$ gene were introduced into CHO cells, and stable transfectants were selected. Total cell RNA $(3 \mu \mathrm{g})$ was analyzed from cells growing exponentially (lanes 1 and 4$)$ and from parallel cultures treated with hydroxyurea (lanes 2 and 5) for $1 \mathrm{~h}$, using an $\mathrm{S} 1$ nuclease protection assay. The probe was the $\mathrm{SL}_{\mathrm{wt}-\mathrm{mut}}$ gene labeled at the $3^{\prime}$ end of the NarI site at codon 43 . The protected fragments are $\mathrm{H}^{2} \mathrm{a}_{\mathbf{H}}$ (protection by the endogenous hamster $\mathrm{H} 2 \mathrm{a}$ mRNAs), $\mathrm{H} 2 \mathrm{a}_{\mathrm{M}-\mathrm{wt}}$ (protection

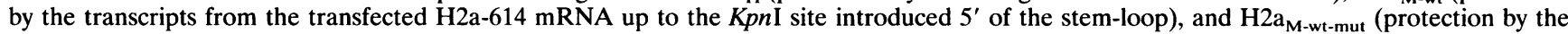
transcripts from the transfected SL $\mathrm{SL}_{\mathrm{wt}-\mathrm{mut}}$ gene). Lanes: 1 and 2, cells transfected with the H2a-614 gene; 3, pUC18 digested with $\mathrm{HpaII} ; 4$ and 5 , cells transfected with the $\mathrm{SL}_{\mathrm{wt} \text {-mut }}$ gene. The minor bands below the $\mathrm{H}_{2} \mathrm{a}_{\mathrm{H}}$ band are derived from the probe and were not affected by the hydroxyurea treatment. (B) RNA $(20 \mu \mathrm{g})$ from cells transfected with the SL(RS) gene was analyzed in an S1 nuclease protection assay. In lanes 1 and 2, the probe was the SL(RS) gene labeled at the $3^{\prime}$ end of $A v a I$ site at codon 20; in lanes 3 and 4, the probe was the H2a-614 gene labeled at the AvaI site. In lanes 2 and 4 , RNA from cells treated with $5 \mathrm{mM}$ hydroxyurea for $1 \mathrm{~h}$ was analyzed. The protected fragments are $\mathrm{H} 2 \mathrm{a}_{\mathrm{H}}$ (protection by the endogenous hamster $\mathrm{H} 2 \mathrm{a}$ mRNAs) and $\mathrm{H} 2 \mathrm{a}_{\mathrm{M}-\mathrm{RT}}$ [protection of read-through transcripts from the transfected SL(RS) gene up to the KpnI site introduced 5' of the stem-loop]. These transcripts are not observed with the SL(RS) probe (lanes 1 and 2) since they do not have defined $3^{\prime}$ ends. Lane M is pUC18 digested with $\mathrm{HpaII}$. (C) In lanes 1 and 2, $30 \mu \mathrm{g}$ of RNA from cells transfected with the SL(CG/CG) gene was assayed by $\mathrm{S} 1$ nuclease mapping using the SL(CG/CG) gene as a probe. The same RNA sample analyzed in lane 2 was analyzed by using the H2a-614 gene as a probe. This probe mapped any transcripts which extend past the histone $3^{\prime}$ end as a single protected fragment (H2a $\left.\mathrm{a}_{\mathrm{M}-\mathrm{RT}}\right)$. Lane 4 is $30 \mu \mathrm{g}$ of RNA from untransfected CHO cells mapped with the SL(CG/CG) probe. The expected position of the $\mathrm{H} 2 \mathrm{a}_{\mathrm{M}}$ band at $410 \mathrm{nt}$ is indicated. The $\mathrm{H}_{2} \mathrm{a}_{\mathrm{H}}$ fragment is a result of protection of the hamster histone H2a mRNAs to the TAA codon. Lane M is pUC18 digested with HpaII. Sizes are indicated in nucleotides.

end of the histone gene (Fig. 2B, lane 1). However, when the same RNA samples were analyzed with the intact H2a-614 gene as a probe, transcripts were detected from the SL(RS) gene, which mapped to the KpnI site before the stem-loop (Fig. $2 \mathrm{~B}$, lane 3 , band $\mathrm{H} 2 \mathrm{a}_{\mathrm{M}-\mathrm{RT}}$ ). These transcripts probably have heterogenous $3^{\prime}$ ends, accounting for the failure to detect them with the homologous probe. The heterogenous transcripts are not degraded when DNA synthesis is inhibited (Fig. 2B, lane 4 ), because they are retained in the nucleus (32, and data not shown) and do not have the stem-loop at the $3^{\prime}$ end of the mRNA $(18,24)$. Thus, changing the sequence of the stem but maintaining the secondary structure of the stem and the loop sequence abolished expression of mature histone mRNA. The fact that unprocessed transcripts can be detected from the transfected genes demonstrates that the SL(RS) gene was successfully transfected into the hamster cells.

A second gene with the two CG base pairs at the base of the stem reversed, SL(CG/CG), was also analyzed. There was no detectable mature mRNA produced from this gene (Fig. 2C, lanes 1 and 2). Note that 10 times as much RNA was analyzed in Fig. $2 \mathrm{C}$ as in Fig. 2A. We estimate that we would have detected expression of $\mathrm{H} 2 \mathrm{a}$ mRNA at $2 \%$ of the wild-type level. (A band with $20 \%$ the intensity of the $\mathrm{H} 2 \mathrm{a}_{M}$ band from the $\mathrm{SL}_{\mathrm{wt}}$ gene would have been detectable, and 10 times as much RNA was analyzed.) When the intact $\mathrm{H} 2 \mathrm{a}-614$ gene was used as a probe, transcripts from the SL(CG/CG) gene were readily detected (Fig. 2C, lane 3 ). These represent unprocessed transcripts which are present at a low level, similar to the level seen for the SL(RS) gene. Thus, we can conclude that these two genes, SL(RS) and SL(CG/CG), were transcribed but that no mature mRNA accumulated from these genes. All of the transcripts which we detected in steady-state RNA extended past the normal histone $3^{\prime}$ end.

A UA base pair at the top of the stem is necessary for high expression. To investigate the role of the conserved UA base pair at the top of the stem, we changed this base pair to a UG or CG base pair. In addition, we constructed genes in which the base pair was abolished, and replaced with UC or UU.

To quantify the expression of the different constructs, we used the following procedure. The same amount of RNA (3 $\mu \mathrm{g})$ from each transfection was analyzed by $\mathrm{S} 1$ nuclease mapping using the wild-type $\mathrm{H} 2 \mathrm{a}-614$ gene as a probe, to ensure that equal amounts of endogenous hamster histone mRNA were present in each pool of cells. This was necessary 


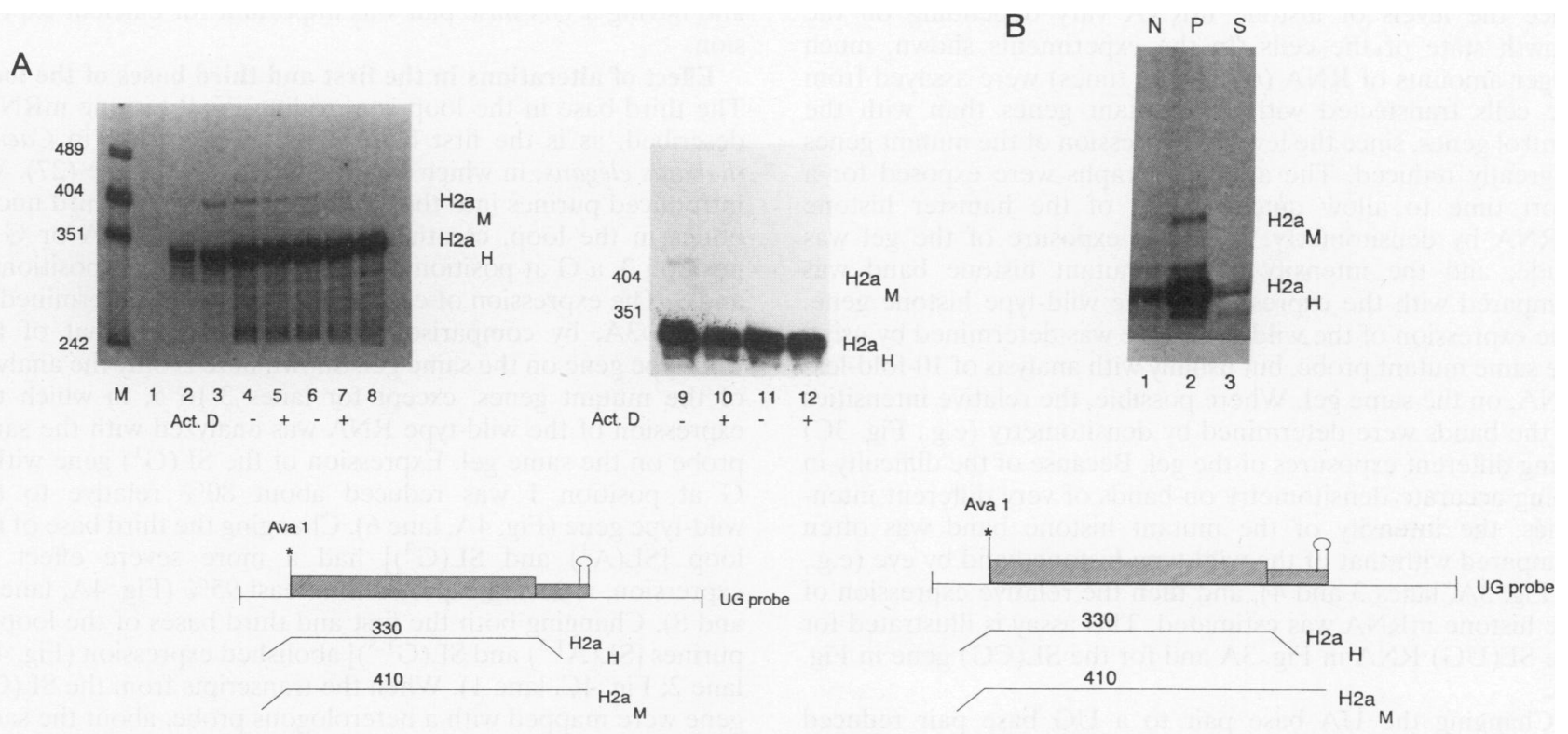

C

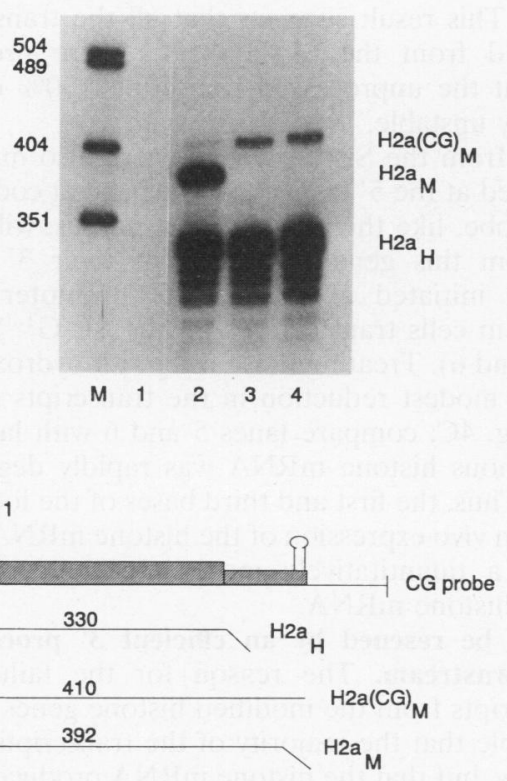

D
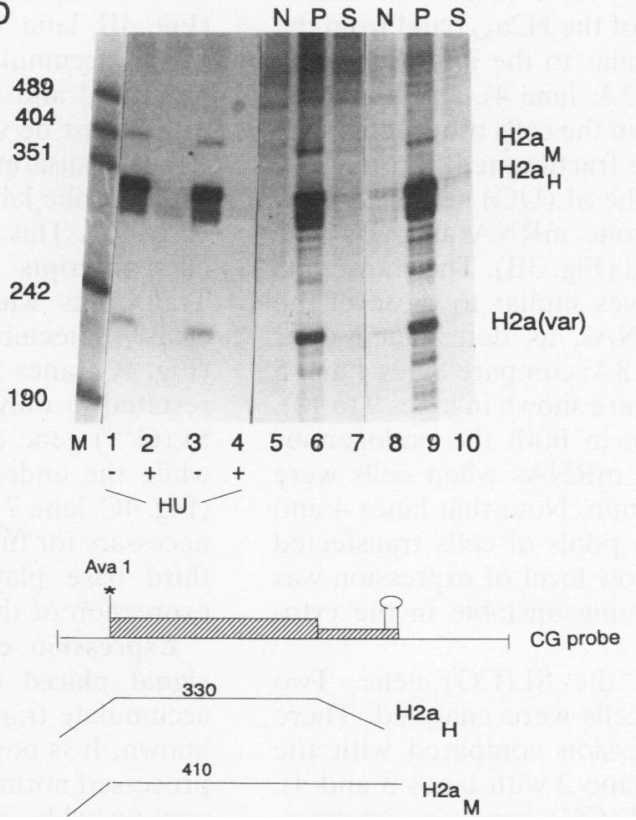

FIG. 3. Expression of the SL(UG) and SL(CG) genes. (A) RNA ( $3 \mu \mathrm{g})$ from CHO cells (lane 2) or CHO cells transfected with the H2a-614 gene (lane 3) was analyzed by S1 nuclease mapping. Duplicate pools of CHO cells transfected with the SL(UG) gene were treated with actinomycin D $(5 \mu \mathrm{g} / \mathrm{ml})$ for $1 \mathrm{~h}$, and $30 \mu \mathrm{g}$ of total cell RNA was analyzed from treated (lanes 5 and 7) and untreated (lanes 4 and 6 ) cells. The probe used was the SL(UG) gene labeled at the 3' end of the AvaI site. Lane 8 is analysis of $30 \mu \mathrm{g}$ of RNA from untransfected CHO cells. Lanes 9 to 12 are lighter exposures of the RNA samples assayed in lanes 4 to 7 . Lane 1 is analysis of $10 \mu \mathrm{g}$ of yeast tRNA, and lane M is pUC18 digested with $H p a$ II. The levels of the RNAs were quantified by densitometry. The protected fragments are $\mathrm{H}_{2} \mathrm{a}_{\mathrm{H}}$ (protection by the endogenous CHO RNAs) and $\mathrm{H} 2 \mathrm{a}_{M}$ (protection by processed transcripts from the transfected genes). The level of expression of the SL(UG) gene was estimated by comparing the intensity of the $\mathrm{H}_{2} \mathrm{a}_{\mathrm{M}}$ band in lane 3 with that in lanes 4 and 6 and correcting for the different amounts of RNA analyzed. (B) Cells transfected with the SL(UG) gene were fractionated into nuclear (N; lane 1), polysomal (P; lane 2), and cytosolic (C; lane 3) fractions, and RNA from equal numbers of cells was analyzed by S1 nuclease mapping using the SL(UG) gene as a probe. The protected fragments are labeled as in panel A. (C) RNA (30

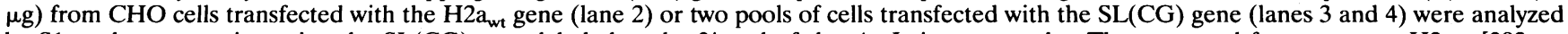
by $\mathrm{S} 1$ nuclease mapping using the SL(CG) gene labeled at the $3^{\prime}$ end of the $A v a I$ site as a probe. The protected fragments are $\mathrm{H} 2 \mathrm{a}_{\mathrm{M}}$ [392 nt; protection of the H2a-614 mRNA to the point of divergence from the $\mathrm{SL}(\mathrm{CG})$ gene] and $\mathrm{H} 2 \mathrm{a}(\mathrm{CG})_{\mathrm{M}}$ [410 nt; protection of the mRNA from the SL(CG) gene to the end of the histone mRNA]. The faint band at $410 \mathrm{nt}$ in lane 2 is due to a failure of S1 nuclease to cleave the mismatched hybrid completely. Lane 1 is analysis of $10 \mu \mathrm{g}$ of yeast tRNA. Lane M is pUC18 digested with HpaII. The level of expression of the SL(CG) gene was quantified with a PhosphorImager. (D) Duplicate pools of cells transfected with the SL(CG) gene were analyzed. RNA (20 $\mu \mathrm{g})$ was analyzed from control cells (lanes 1 and 3 ) and from cells treated with hydroxyurea (HU; lanes 2 and 4 ) for $1 \mathrm{~h}$. Lanes 5 to 10 are analyses of RNA from cells which were fractionated into nuclear $(\mathrm{N})$, polysomal $(\mathrm{P})$, and cytosolic (S) fractions. The protected fragments are $\mathrm{H}_{2} \mathrm{a}_{\mathbf{H}}$ (protection by the endogenous CHO RNAs) and $\mathrm{H}_{2} \mathrm{a}_{M}$ [protection by processed transcripts from the SL(CG) gene]. The 235 -nt fragment is protection by the variant $\mathrm{H} 2 \mathrm{a} .1$ histone mRNAs to the point of divergence from the probe at codon 99. Lane M is pUC18 digested with HpaII. Sizes are indicated in nucleotides. 
since the levels of histone mRNA vary depending on the growth state of the cells. In the experiments shown, much larger amounts of RNA (usually 10 times) were assayed from the cells transfected with the mutant genes than with the control genes, since the level of expression of the mutant genes is greatly reduced. The autoradiographs were exposed for a short time to allow quantification of the hamster histone mRNA by densitometry. A longer exposure of the gel was made, and the intensity of the mutant histone band was compared with the expression of the wild-type histone gene. The expression of the wild-type gene was determined by using the same mutant probe, but usually with analysis of 10 -fold-less RNA, on the same gel. Where possible, the relative intensities of the bands were determined by densitometry (e.g., Fig. 3C) using different exposures of the gel. Because of the difficulty in doing accurate densitometry on bands of very different intensities, the intensity of the mutant histone band was often compared with that of the wild-type histone band by eye (e.g., in Fig. 3A, lanes 3 and 4), and then the relative expression of the histone mRNA was estimated. This assay is illustrated for the SL(UG) RNA in Fig. 3A and for the SL(CG) gene in Fig. $3 \mathrm{C}$.

Changing the UA base pair to a UG base pair reduced expression of the histone mRNA by $90 \%$ (Fig. 3A). This is readily apparent since the intensity of the $\mathrm{H} 2 \mathrm{a}_{M}$ band from the $\mathrm{H} 2 \mathrm{a}_{\mathrm{wt}}$ gene (Fig. 3A, lane 3) is similar to the intensity of the band from the SL(UG) gene (Fig. 3A, lane 4), and there was 10 times as much RNA analyzed from the cells transfected with the SL(UG) gene. When cells were fractionated into nuclear, polysomal, and cytosolic fractions, the SL(UG) mRNA cofractionated with the endogenous histone mRNA and was predominantly found on polyribosomes (Fig. 3B). The transcripts from the SL(UG) gene had half-lives similar to those of the endogenous hamster histone mRNAs, as determined after treatment with actinomycin D (Fig. 3A; compare lanes 4 and 5 and lanes 6 and 7; lighter exposures are shown in lanes 9 to 12). There was about a $50 \%$ reduction in both the endogenous histone mRNAs and the SL(UG) mRNAs when cells were treated with actinomycin $\mathrm{D}$ for $60 \mathrm{~min}$. Note that lanes 4 and 6 are analyses of two independent pools of cells transfected with the SL(UG) gene. Thus, the low level of expression was not due to the SL(UG) mRNA being unstable in the cytoplasm.

Similar results were seen with the SL(CG) gene. Two independent pools of transfected cells were analyzed. There was a reduction of $80 \%$ in expression compared with the wild-type gene (Fig. 3C; compare lane 2 with lanes 3 and 4). The mRNA produced from the SL(CG) gene was quantitatively localized to polyribosomes (Fig. 3D, lanes 6 and 9) and was rapidly degraded when cells were treated with hydroxyurea to inhibit DNA synthesis (Fig. 3D, lanes 2 and 4). Thus, changing the top base pair reduced accumulation of histone mRNA without altering the half-life or the ability of the RNA to be transported to the cytoplasm.

Changing the UA base pair to UC essentially abolished expression (Fig. 4A, lane 1), and there was very low expression ( $<5 \%$ of wild-type) of the SL(UU) mRNA (Fig. 4A, lane 4). We did not detect any expression when the top base pair was changed to AG (not shown). The same RNA samples were mapped with a heterologous probe, the wild-type H2a-614 probe. There were transcripts detected from the transfected genes, indicating that the genes were transcribed but not (or very inefficiently) processed (Fig. 4B, lanes 2 and 3). Thus, changes in the top base pair of the stem, either to strengthen the base pair or to abolish the base pair, greatly reduced expression. Having a six-base stem was critical for expression, and having a UA base pair was important for efficient expression.

Effect of alterations in the first and third bases of the loop. The third base in the loop is a uridine in all histone mRNAs described, as is the first base in the loop, except in Caenorhabditis elegans, in which the first base is a cytosine (27). We introduced purines into the conserved first and/or third nucleotides in the loop, creating genes which had an $A$ or $G$ at position 3, a G at position 1, or A's or G's at both positions 1 and 3. The expression of each mutant gene was determined as in Fig. 3A, by comparison of expression with that of the wild-type gene on the same gel. Shown here is only the analysis of the mutant genes, except for lanes 3 to 5 , in which the expression of the wild-type RNA was analyzed with the same probe on the same gel. Expression of the $\mathrm{SL}\left(\mathrm{G}^{1}\right)$ gene with a $G$ at position 1 was reduced about $80 \%$ relative to the wild-type gene (Fig. 4A, lane 6). Changing the third base of the loop $\left[\operatorname{SL}\left(\mathrm{A}^{3}\right)\right.$ and $\left.\operatorname{SL}\left(\mathrm{G}^{3}\right)\right]$ had a more severe effect on expression, reducing expression at least $95 \%$ (Fig. 4A, lanes 5 and 8). Changing both the first and third bases of the loop to purines $\left[\operatorname{SL}\left(\mathrm{A}^{1,3}\right)\right.$ and $\left.\operatorname{SL}\left(\mathrm{G}^{1,3}\right)\right]$ abolished expression (Fig. 4A, lane 2; Fig. $4 \mathrm{C}$, lane 1). When the transcripts from the $\operatorname{SL}\left(\mathrm{G}^{1}\right)$ gene were mapped with a heterologous probe, about the same level of expression was seen as with the homologous probe (Fig. 4B, lane 1). This result suggests that all the transcripts which accumulated from the $\operatorname{SL}\left(G^{1}\right)$ gene were properly processed and that the unprocessed transcripts $(80 \%$ of the total) must be very unstable.

The transcripts from the $\operatorname{SL}\left(\mathrm{G}^{1,3}\right)$ gene were also mapped with a probe labeled at the $5^{\prime}$ end of the NarI site at codon 43 (Fig. 4C). This probe, like the heterologous probes, will map all transcripts from this gene regardless of their $3^{\prime}$ ends. Transcripts which initiated at the histone promoter were clearly detectable in cells transfected with the $\operatorname{SL}\left(G^{1,3}\right)$ gene (Fig. 4C, lanes 5 and 6). Treating these cells with hydroxyurea resulted in only a modest reduction in the transcripts of the $\mathrm{SL}\left(\mathrm{G}^{1,3}\right)$ gene (Fig. 4C; compare lanes 5 and 6 with lane 7), while the endogenous histone mRNA was rapidly degraded (Fig. 4C, lane 7). Thus, the first and third bases of the loop are necessary for full in vivo expression of the histone mRNA. The third base plays a quantitatively more important role in expression of the histone mRNA.

Expression can be rescued by an efficient $3^{\prime}$ processing signal placed downstream. The reason for the failure to accumulate transcripts from the modified histone genes is not known. It is possible that the majority of the transcripts were processed normally, but that the histone mRNA produced was very unstable, either in the nucleus or in the cytoplasm. It is also possible that the defect is in the processing of the histone mRNA and that the unprocessed histone mRNA was rapidly degraded. To distinguish between these two possibilities, we attached an efficient $3^{\prime}$ processing signal, either the mouse $\beta$-globin polyadenylation site or the wild-type histone $\mathrm{H} 2 \mathrm{a}-614$ $3^{\prime}$ processing signal downstream of the mutant histone $3^{\prime}$ processing signal (Fig. 1C).

We reasoned that if the pre-mRNAs were not processed rapidly, then transcription would continue to the downstream processing site and the RNA would be processed at this site, forming a defined long transcript. In contrast, if the histone mRNA were efficiently processed and rapidly degraded, then no longer transcripts should be detected. Previously we have shown that when this polyadenylation site is placed $3^{\prime}$ of an efficient histone processing signal, then the polyadenylation site is not used, presumably because the transcripts are processed prior to transcription reaching the polyadenylation site $(15,23)$. 
A
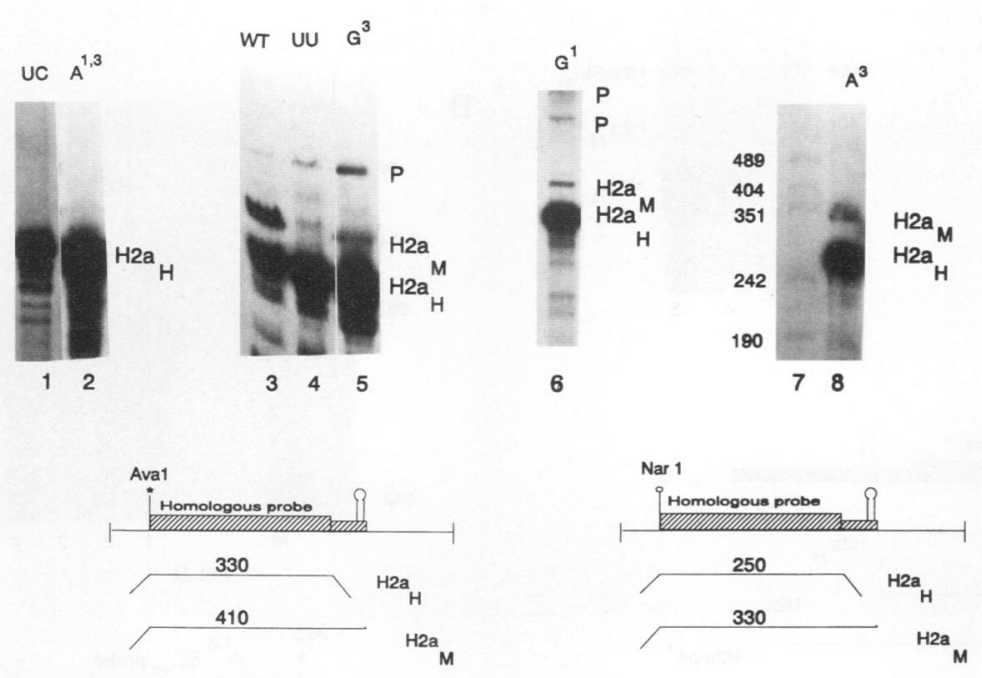

$G^{1}$ UU UC

C
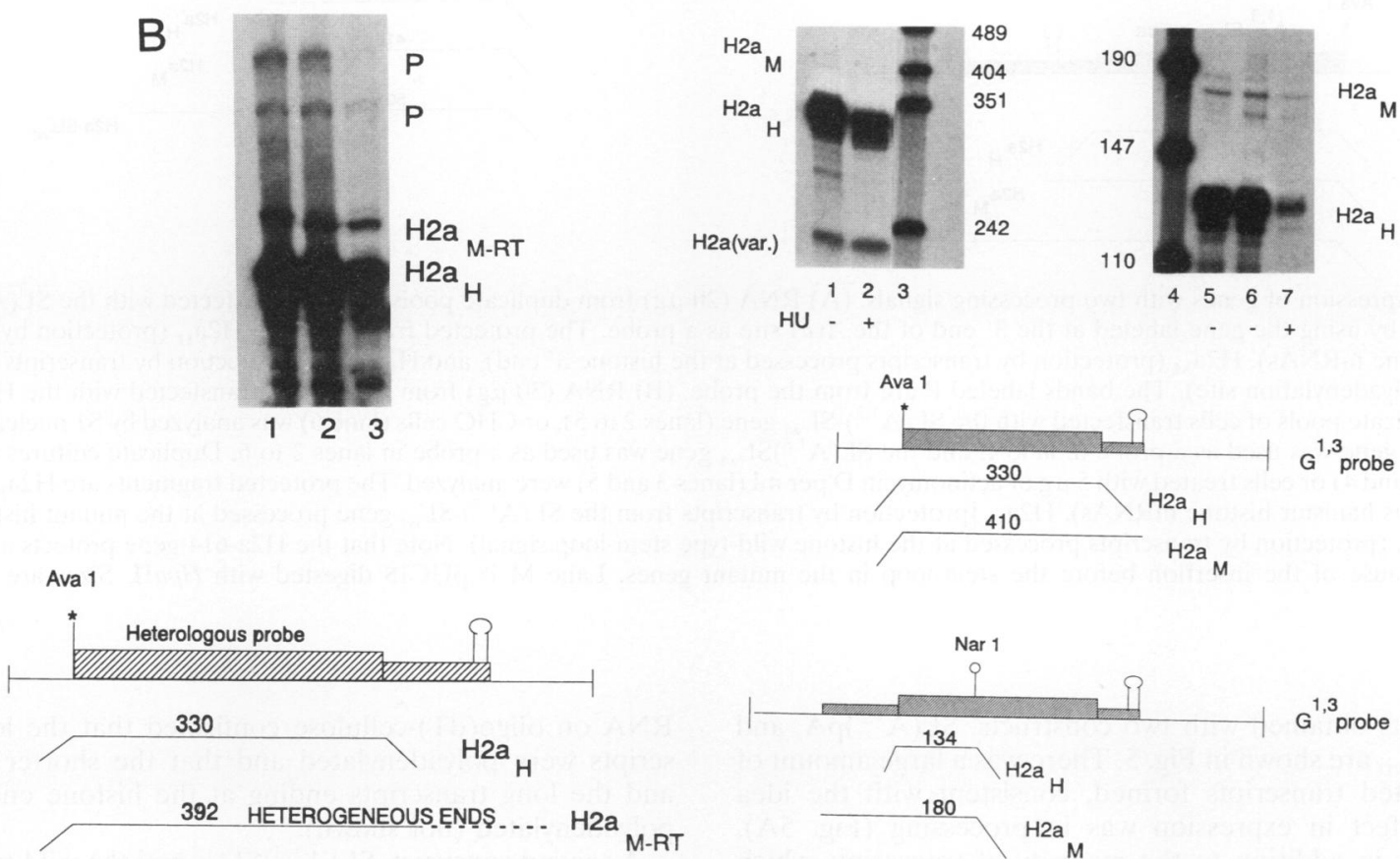

FIG. 4. Expression of histone mRNA from genes with mutations in the stem-loop. (A) RNA (30 $\mu \mathrm{g})$ from cells transfected with the mutant histone genes (the mutant gene is indicated above each lane) was analyzed by S1 nuclease mapping, except for lane 3, in which $5 \mu \mathrm{g}$ of RNA from cells transfected with the H2a-614 gene was analyzed. The homologous probe labeled at the $3^{\prime}$ end of the $A v a$ I site at codon 20 was used, except in lane 8 , in which the probe was labeled at the $3^{\prime}$ end of the NarI site at codon 43 . These probes will map only the properly processed mRNA. The protected fragments are $\mathrm{H}_{2} \mathrm{a}_{\mathrm{H}}$ (protection by the endogenous CHO RNAs) and $\mathrm{H} 2 \mathrm{a}_{\mathrm{M}}$ (protection by processed transcripts from the transfected genes). The band labeled $\mathrm{P}$ is from the probe. Lane 7 is pUC18 digested with HpaII. The level of expression of the mutant RNAs was estimated by comparing the intensities of the $\mathrm{H} 2 \mathrm{a}_{M}$ band from cells transfected with the $\mathrm{H} 2 \mathrm{a}-614$ gene with the expression of the mutant genes and correcting for the different amounts of RNA analyzed. In this gel, we show only the analysis of the mutant genes, except for lane 3, in which expression of the wild-type H2a-614 gene is shown for comparison. (B) RNA (30 $\mu \mathrm{g})$ from cells transfected with the SL(G'), SL(UU), or SL(UC) gene was analyzed by $\mathrm{S} 1$ nuclease mapping using the $\mathrm{H} 2 \mathrm{a}-614$ gene labeled at the $A v a \mathrm{I}$ site $\mathrm{t}$ codon 20 as a probe. This probe protects all of the transcripts from the transfected genes as a single fragment mapping point where there was a 6-nt insertion before the stem-loop in the mutant genes

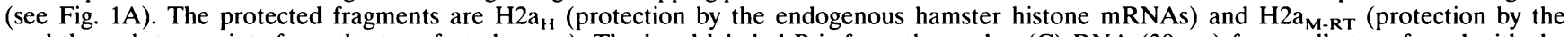
read-through transcripts from the transfected genes). The band labeled P is from the probe. (C) RNA (30 $\mu \mathrm{g})$ from cells transfected with the SL $\left(G^{1.3}\right)$ gene was analyzed by S1 nuclease mapping. Duplicate pools of cells were assayed in lanes 5 and 6 . RNA was from untreated cells (lanes 1,5 , and 6 ) or cells treated with $5 \mathrm{mM}$ hydroxyurea (HU) (lanes 2 and 7) for $1 \mathrm{~h}$. The probes used were the SL(G $\mathrm{G}^{1.3}$ ) gene labeled at the $3^{\prime}$ end (lanes 1 and 2) or the $5^{\prime}$ end (lanes 5 to 7 ) of the Narl site at codon 43. The protected fragments are $\mathrm{H}_{2} \mathrm{a}_{\mathbf{H}}$ (protection by the endogenous hamster histone mRNAs) and $\mathrm{H}_{2} \mathrm{a}_{\mathrm{M}}$ (position of the processed transcripts from the transfected genes [lanes 1 and 2] or protection by all transcripts from the transfected genes [lanes 5 to 7]). Lanes 3 and 4 are pUC18 digested with $\mathrm{HpaII}$. Sizes are indicated in nucleotides. 
A
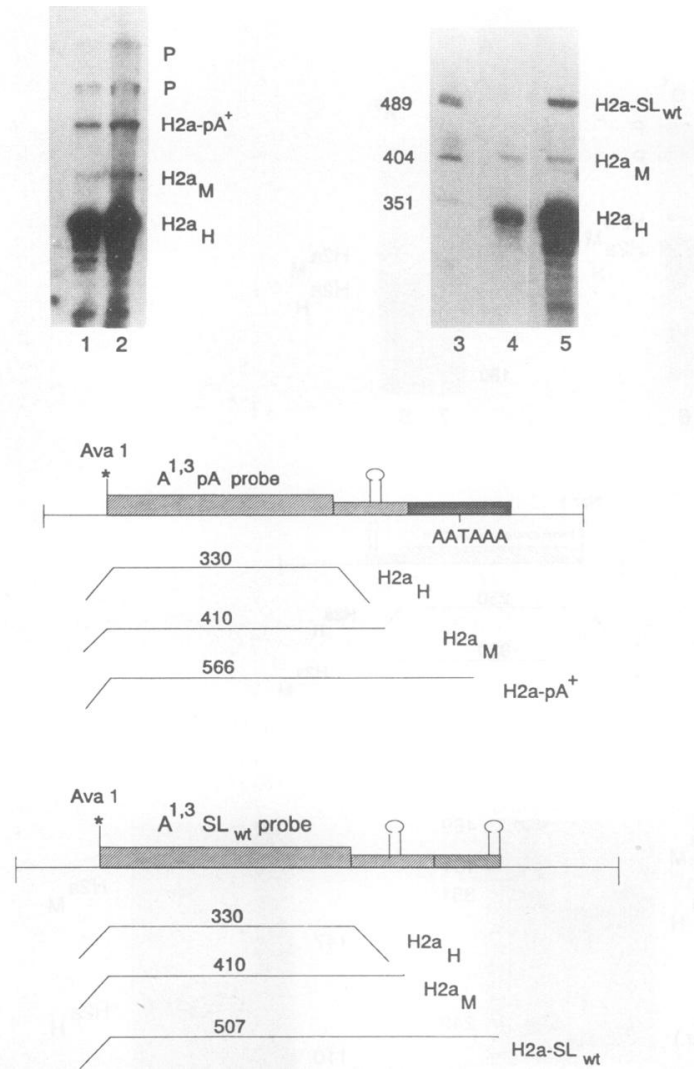

B
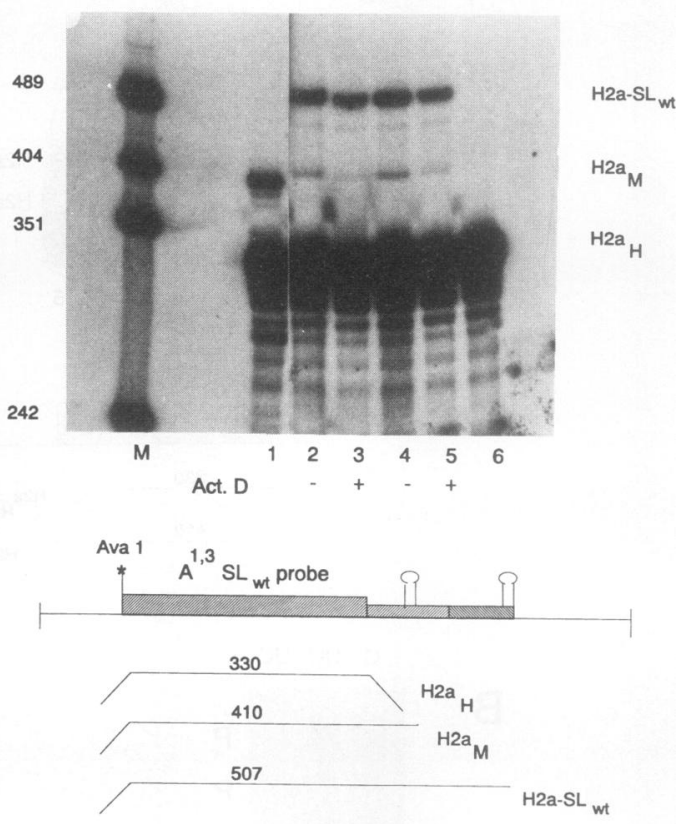

FIG. 5. Expression of genes with two processing signals. (A) RNA $(20 \mu \mathrm{g})$ from duplicate pools of cells transfected with the SL( $\left.\mathrm{A}^{1,3}\right)$ pA gene was analyzed by using the gene labeled at the $3^{\prime}$ end of the $A v a$ I site as a probe. The protected fragments are $\mathrm{H}_{2} \mathrm{a}_{\mathrm{H}}$ (protection by endogenous hamster histone mRNAs), $\mathrm{H}_{2} \mathrm{a}_{\mathrm{M}}$ (protection by transcripts processed at the histone $3^{\prime}$ end), and $\mathrm{H}_{2} \mathrm{a}-\mathrm{pA}^{+}$(protection by transcripts processed at the globin polyadenylation site). The bands labeled $\mathrm{P}$ are from the probe. (B) RNA (30 $\mu \mathrm{g})$ from CHO cells transfected with the H2a-614 gene (lane 1), duplicate pools of cells transfected with the $\mathrm{SL}\left(\mathrm{A}^{1.3}\right)-\mathrm{SL}_{\mathrm{wt}}$ gene (lanes 2 to 5), or $\mathrm{CHO}$ cells (lane 6 ) was analyzed by $\mathrm{S} 1$ nuclease mapping. The $\mathrm{H} 2 \mathrm{a}-614$ gene was used as a probe in lane 1, and the $\mathrm{SL}\left(\mathrm{A}^{1.3}\right) \mathrm{SL}_{\mathrm{wt}}$ gene was used as a probe in lanes 2 to 6 . Duplicate cultures of untreated cells (lanes 2 and 4 ) or cells treated with $5 \mu \mathrm{g}$ of actinomycin D per ml (lanes 3 and 5) were analyzed. The protected fragments are $\mathrm{H}_{2} \mathrm{a}_{\mathbf{H}}($ protection by endogenous hamster histone mRNAs), $\mathrm{H} 2 \mathrm{a}_{\mathrm{M}}$ [protection by transcripts from the $\mathrm{SL}\left(\mathrm{A}^{1,3}\right)-\mathrm{SL}_{\mathrm{wt}}$ gene processed at the mutant histone $3^{\prime}$ end], and $\mathrm{H} 2 \mathrm{a}-\mathrm{SL}_{\mathrm{wt}}$ (protection by transcripts processed at the histone wild-type stem-loop signal). Note that the $\mathrm{H} 2 \mathrm{a}-614$ gene protects a 6-nt-shorter fragment because of the insertion before the stem-loop in the mutant genes. Lane M is pUC18 digested with HpaII. Sizes are indicated in nucleotides.

The results obtained with two constructs, $\operatorname{SL}\left(\mathrm{A}^{1,3}\right) \mathrm{pA}$, and $\operatorname{SL}\left(A^{1,3}\right) S L_{w t}$, are shown in Fig. 5. There was a large amount of polyadenylated transcripts formed, consistent with the idea that the defect in expression was in processing (Fig. 5A). Surprisingly, in addition to the majority of transcripts which ended at the globin polyadenylation site, we also observed some transcripts which ended at the histone $3^{\prime}$ end (Fig. 5A, lanes 1 and 2). No transcripts which ended at the histone $3^{\prime}$ end were formed on the $\operatorname{SL}\left(\mathrm{A}^{1,3}\right)$ gene which lacked the downstream polyadenylation signal (Fig. 4A, lane 2). This finding suggests that the transcripts ending at the histone end from the $\operatorname{SL}\left(\mathrm{A}^{1,3}\right) \mathrm{pA}$ gene were formed as a result of the presence of the downstream polyadenylation site. The formation of histone mRNAs ending at the $\operatorname{SL}\left(\mathrm{A}^{1,3}\right)$ stem-loop was $10 \%$ of the amount of the transcripts which were polyadenylated. The amount of transcripts ending at the polyadenylation site was similar to the amount of transcripts produced when the wild-type $\mathrm{H} 2 \mathrm{a}-614$ gene was introduced into $\mathrm{CHO}$ cells, suggesting that the failure to form histone $3^{\prime}$ ends on these transcripts was due to inefficient processing in vivo. Transcription continued past the mutant stem-loop to the polyadenylation site, which is then used efficiently. Chromatography of the
RNA on oligo(dT)-cellulose confirmed that the longer transcripts were polyadenylated and that the shorter transcripts and the long transcripts ending at the histone end were not polyadenylated (not shown).

A second construct, $\operatorname{SL}\left(\mathrm{A}^{1,3}\right) \mathrm{SL}_{\mathrm{w}}$, had the wild-type histone processing signal placed $3^{\prime}$ of the $\operatorname{SL}\left(A^{1,3}\right)$ gene. As with the SL $\left(A^{1,3}\right)$ pA gene, we detected two transcripts: the major one, which protected a longer 507-nt fragment ending at the downstream histone $3^{\prime}$ end site, and the minor one, protecting a 410-nt fragment ending at the $\operatorname{SL}\left(\mathrm{A}^{1.3}\right)$ stem-loop (Fig. 5A, lane 5). The SL( $\left.A^{1,3}\right) 3^{\prime}$ end was formed at $10 \%$ of the level of the wild-type histone gene (Fig. 5A; compare lanes 4 and 5). The absolute expression of these transcripts was similar to that observed from the SL $\left(\mathrm{A}^{1,3}\right) \mathrm{pA}$ gene, again consistent with the activation of processing at the $\operatorname{SL}\left(\mathrm{A}^{1,3}\right)$ stem-loop as a result of placing an efficient processing signal downstream. When cells were treated with actinomycin $D$ for $1 \mathrm{~h}$, the $\operatorname{SL}\left(\mathrm{A}^{1,3}\right)$ transcripts were reduced three- to fourfold, while the endogenous histone mRNAs and the longer transcripts ending at histone $3^{\prime}$ ends were reduced about 50\% (Fig. 5B; compare lanes 2 and 3 and lanes 4 and 5). Thus, the transcripts ending at the $\operatorname{SL}\left(\mathrm{A}^{1,3}\right)$ stem-loop were somewhat more unstable but not extremely 


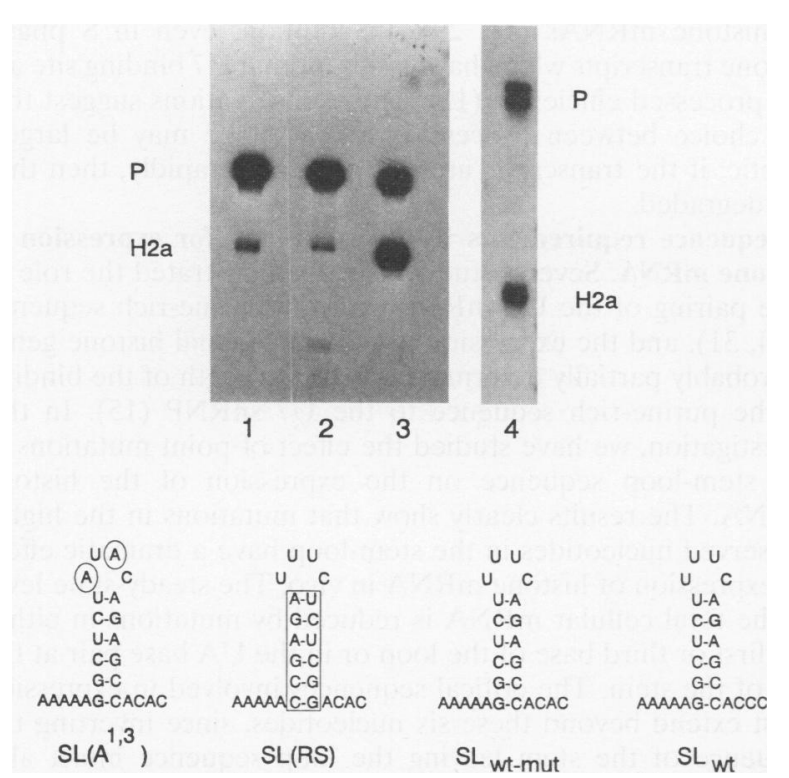

FIG. 6. Processing of mutant histone signals in vitro. Synthetic precursor RNAs starting at the PstI site at codon 85 and extending 35 nt past the $3^{\prime}$ end of the histone mRNA were synthesized from the $\operatorname{SL}\left(\mathrm{A}^{1,3}\right)$, the SL(RS), and the $\mathrm{SL}_{\mathrm{wt}-\mathrm{mut}}$ genes and purified by preparative polyacrylamide gel electrophoresis. The transcripts were incubated in a HeLa cell nuclear extract for $1 \mathrm{~h}$ in a final volume of $10 \mu \mathrm{l}$ as described previously (2). In lane 4 is shown the processing of the $\mathrm{SL}_{\mathrm{wt}}$ analyzed in a parallel experiment with the same extract; $6 \times$ $10^{-16}$ to $8 \times 10^{-16} \mathrm{~mol}$ of substrate was used. The RNAs were subsequently analyzed by gel electrophoresis and detected by autoradiography. The band labeled $\mathrm{P}$ is the input pre-mRNA, and the band labeled $\mathrm{H} 2 \mathrm{a}$ is the processed mRNA.

unstable compared with processed transcripts from the normal histone genes. If processed transcripts had been formed from the $\operatorname{SL}\left(\mathrm{A}^{1,3}\right)$ gene, they certainly would have been detected (Fig. 4A, lane 2).

We conclude that the reason for the lack of expression of the mutant histone mRNAs was a failure to process the mRNAs in vivo. For some reason, the addition of a downstream functional 3 ' processing signal, either a polyadenylation site or a histone processing signal, allowed some processing of the mutant $\operatorname{SL}\left(\mathrm{A}^{1,3}\right)$ pre-mRNA at the histone processing site. It is possible that the addition of a distal processing site stabilizes the pre-mRNA, allowing eventual processing to give the histone $3^{\prime}$ end (see Discussion).

Processing of the mutant stem-loop mRNA precursors in vitro. A synthetic histone H2a-614 mRNA precursor can be efficiently processed in a HeLa cell nuclear extract (2) or a mouse myeloma cell nuclear extract (15). To test the relative ability of some of the mutant pre-mRNAs to be processed in vitro, we synthesized synthetic pre-mRNA transcripts extending from the PstI site at codon 83 in the H2a gene to the HpaII site $35 \mathrm{nt} 3^{\prime}$ of the normal end of the histone mRNA. These transcripts were incubated with a HeLa cell nuclear extract in a parallel reaction with the synthetic $\mathrm{SL}_{\mathrm{wt}-\mathrm{mut}}$ pre-mRNA. The pre-mRNA from the $\mathrm{SL}_{\mathrm{wt}-\mathrm{mut}}$ gene, which has the changes in the sequences flanking the stem-loop, was processed efficiently (Fig. 6, lane 3), with the same efficiency as the $\mathrm{SL}_{\mathrm{wt}}$ pre-mRNA (Fig. 6, lane 4). Thus, altering the sequence between the stem-loop and the U7 binding site did not affect the ability of the pre-mRNA to be processed in vitro. In contrast, the $\operatorname{SL}\left(\mathrm{A}^{1,3}\right)$ gene with $\mathrm{A}^{\prime} \mathrm{s}$ in positions 1 and 3 of the loop was
A

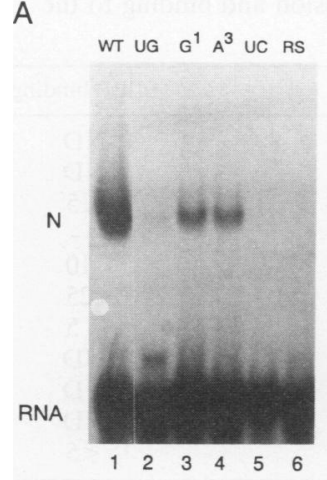

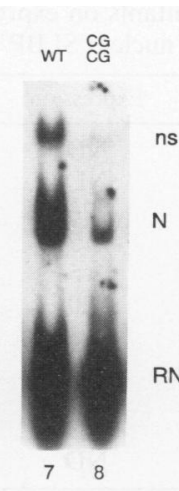

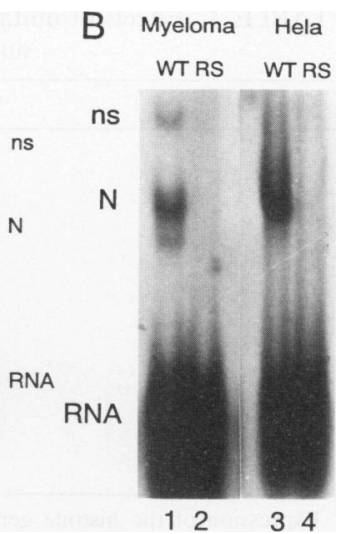

FIG. 7. Binding of mutant stem-loops to nuclear proteins. (A) Synthetic 30-nt RNAs containing the wild-type stem-loop (lane 1) and the same RNA except for changes in the stem-loop indicated above each lane, using the nomenclature of Fig. 1B, were prepared by using T7 RNA polymerase and oligonucleotide templates as described previously (25). The synthetic RNAs were incubated with $12 \mu \mathrm{g}$ of nuclear protein from mouse myeloma cells in the presence of $30 \mu \mathrm{g}$ of tRNA and analyzed by polyacrylamide gel electrophoresis under nondenaturing conditions. The band labeled RNA is the synthetic probe, and the band labeled $\mathrm{N}$ is a complex formed with nuclear proteins. Lanes 7 and 8 represent an independent assay with a different preparation of nuclear extract. This preparation gave a nonspecific band (labeled ns). (B) Synthetic 30-nt RNAs containing the wild-type stem-loop (lanes 1 and 3) or the reverse-stem (RS) mutation (lanes 2 and 4) were incubated with $12 \mu \mathrm{g}$ of protein from mouse myeloma cell or $20 \mu \mathrm{g}$ of $\mathrm{HeLa}$ cell nuclear extract as described for panel A. A similar complex $(\mathrm{N})$ was formed on the wild-type stem-loop in each extract. The position of the unbound RNA is indicated.

processed poorly, less than $5 \%$ as efficiently as the wild-type histone mRNA (Fig. 6, lane 1). The synthetic SL(RS) precursor was processed even less efficiently than the $\operatorname{SL}\left(\mathrm{A}^{1,3}\right)$ precursor (Fig. 6, lane 2). Thus, the in vitro assay reflects the relative ability of these mutant genes to be processed in vivo. Taken together, these results show that the sequence of the stem-loop is critical for efficient histone pre-mRNA processing in vivo and support the idea that the reduced expression of these genes in vivo is due to a failure to process the premRNAs.

The efficiency of expression in vivo is correlated with the affinity of the mutant for the SLBP. We have recently described a protein factor which specifically recognizes the stem-loop sequence at the $3^{\prime}$ end of histone mRNA (25). This factor is located both in the nucleus and in the cytoplasm, and it is possible that the nuclear factor plays a role in histone mRNA biosynthesis, in processing, and/or in mRNA transport. We synthesized several synthetic RNAs containing the same mutations in the stem-loop sequence that we tested in vivo and determined the ability of these RNAs to form a complex with the SLBP. We have previously shown that there is no detectable binding of the SLBP to the SL $\left(\mathrm{A}^{1,3}\right)$ mutant and that the SLBP binds with reduced affinity to the $\operatorname{SL}\left(\mathrm{A}^{3}\right)$ and SL(CG) mutant (25). As shown in Fig. 7, the ability of the stem-loop to interact with the SLBP is greatly reduced by the same alterations in the stem-loop sequence which reduce the expression of the mRNA in vivo. Mutants with a single base change in the first or third base of the loop showed reduced binding relative to the wild-type RNA (Fig. 7A, lanes 3 and 4) but bound better than the SL(UG) mutant (Fig. 7A, lane 2). There was no detectable binding to the SL(UC) and SL(RS) mutants (Fig. 
TABLE 1. Effects of mutants on expression and binding to the nuclear SLBP ${ }^{a}$

\begin{tabular}{lcc}
\hline \multicolumn{1}{c}{ Gene } & Expression & SLBP binding \\
\hline SL( $\left.\mathrm{A}^{1,3}\right)$ & ND & ND \\
SL(G $\left.\mathrm{G}^{1,3}\right)$ & ND & ND \\
SL(G $\left(\mathrm{G}^{1}\right)$ & 20 & 15 \\
SL(G & $<5$ & - \\
SL(A $\left.{ }^{3}\right)$ & $<5$ & 10 \\
SL(CG) & 20 & 25 \\
SL(UG) & 5 & 5 \\
SL(UC) & ND & ND \\
SL(UU) & $<5$ & ND \\
SL(RS) & ND & ND \\
SL(CG/CG) & ND & $<5$ \\
\hline
\end{tabular}

${ }^{a}$ Expression of the histone genes was measured by comparing the relative levels of expression of the transfected genes with the level of the endogenous hamster histone mRNA in an S1 nuclease protection assay. The binding of each of the stem-loop sequences was measured from the relative amounts of probe which formed a complex in the mobility shift assay compared with the $\mathrm{SL}_{\mathrm{wt}}$ probe. Values for the wild type were arbitrarily set at 100 . ND, not detectable ( $<2 \%$ of wild-type expression); - , not determined. For each mutant, two independent pools of stable transfectants were analyzed on the same gel with the wild-type $\mathrm{H} 2 \mathrm{a}-614$ gene $\mathrm{SL}_{\mathrm{wt}}$. Where possible, the data were quantified by densitometry of the autoradiograms or by using a PhosphorImager. In other cases, expression was estimated by comparing the intensity of the transfected histone mRNA and correcting for the different amounts of RNA loaded on the gel. Details of quantitation are discussed in the text (see Fig. 3A and C).

$7 \mathrm{~A}$, lanes 5 and 6$)$ and less than $5 \%$ binding of the SL(CG/CG) mutant (Fig. 7A, compare lanes 7 and 8).

A similar complex is formed on the stem-loop in extracts from both mouse myeloma cells and HeLa cells (Fig. 7B). The complex from mouse and human cells has the same electrophoretic mobility. Like the mouse SLBP, the human SLBP does not bind to the SL(RS) (Fig. 7B, lane 4). The other mutants bind similarly to the SLBP in both mouse and human nuclear extracts (not shown). In addition, the binding specificities of the nuclear SLBP and the polyribosomal SLBP are similar (reference 25 and data not shown).

The relative binding affinities to the SLBP were parallel to the relative expression of the mRNA in vivo (Table 1). Those genes which had $3^{\prime}$ ends which did not bind with the SLBP did not form processed histone mRNAs in vivo. This result is consistent with the suggestion that the SLBP plays a critical role in the expression of the histone mRNAs. Since the mutations clearly affect the processing efficiency of the histone mRNAs in vivo, it is likely that the nuclear SLBP is involved in the processing reaction.

\section{DISCUSSION}

The formation of the mature histone mRNA requires only a single processing step, an endonucleolytic cleavage to form the 3 ' end of histone mRNA (1). There are two sequence elements required for efficient processing, a conserved stem-loop sequence present at the $3^{\prime}$ ends of all histone mRNAs and a purine-rich region $3^{\prime}$ of the stem-loop which binds the U7 snRNP by base pairing with the $5^{\prime}$ end of U7 snRNA. Cleavage may occur prior to termination of transcription and result in release of the nascent RNA from the chromatin template, or it may occur after termination of transcription has released a defined pre-mRNA. An alternative fate of the pre-mRNA is that it is degraded, a process referred to as wastage, rather than processed. How the cell makes the choice between processing and wastage is not understood. However, it is clear that many normal histone transcripts are not processed under some conditions. In $G_{1}$ phase, the efficiency of processing is low for all histone mRNAs $(11,29)$. In addition, even in $\mathrm{S}$ phase, histone transcripts which have a suboptimal U7 binding site are not processed efficiently (15). These observations suggest that the choice between processing and wastage may be largely kinetic; if the transcripts are not processed rapidly, then they are degraded.

Sequence requirements in the stem-loop for expression of histone mRNA. Several studies have demonstrated the role of base pairing of the U7 snRNP with the purine-rich sequence $(2,4,31)$, and the expression level of individual histone genes is probably partially determined by the strength of the binding of the purine-rich sequence to the U7 snRNP (15). In this investigation, we have studied the effect of point mutations in the stem-loop sequence on the expression of the histone mRNA. The results clearly show that mutations in the highly conserved nucleotides in the stem-loop have a dramatic effect on expression of histone mRNA in vivo. The steady-state level of the total cellular mRNA is reduced by mutations in either the first or third base of the loop or in the UA base pair at the top of the stem. The critical sequences involved in expression must extend beyond these six nucleotides, since inverting the sequence of the stem leaving the loop sequence intact also abolished expression. Indeed, the sequence of the stem may be as critical as the sequence of the loop, since inverting the two conserved base pairs at the base of the stem alone abolished expression. Thus, the conserved pattern of purines and pyrimidines in the stem may create a structure which is an important element required for expression.

The defect in expression is due to a failure to process the histone pre-mRNA. The decrease in expression of the mutant histone mRNAs could be due to a defect in any of several steps in histone mRNA metabolism. These include failure to process the histone $3^{\prime}$ end; rapid degradation of the histone mRNA in the nucleus, resulting in failure to transport the histone pre-mRNA to the cytoplasm; or rapid degradation of histone mRNA in the cytoplasm. Since the stem-loop at the $3^{\prime}$ end of histone mRNA is known to be involved in regulating the half-life of the histone mRNA in the cytoplasm $(8,24)$ and is also involved in transport of the histone mRNA to the cytoplasm $(5,31 \mathrm{a})$, as well as being required for formation of the $3^{\prime}$ end, defects in any one of these three parameters could result from mutations in the stem-loop.

To distinguish among these possibilities, we constructed genes with efficient $3^{\prime}$ processing sites located $3^{\prime}$ of the mutant $3^{\prime}$ end. We have previously shown that distal polyadenylation signals are not utilized when they are placed in the wild-type gene $(15,23)$. When the $\operatorname{SL}\left(\mathrm{A}^{1,3}\right) \mathrm{pA}$ and $\operatorname{SL}\left(\mathrm{A}^{1,3}\right)-\mathrm{SL}_{\mathrm{wt}}$ genes were introduced into $\mathrm{CHO}$ cells, the major transcripts formed ended at the distal $3^{\prime}$ end, whether that site was a polyadenylation site or a histone $3^{\prime}$ end. The amount of the transcripts which accumulated was similar to the amount of transcripts which accumulated from the wild-type histone gene (Fig. 5). These transcripts could have been formed only if processing at the mutant $3^{\prime}$ signal was inefficient, allowing the RNA polymerase to transcribe through the distal $3^{\prime}$ end signal prior to utilization of the mutant $3^{\prime}$ end signal.

Note that the results with the constructs with two stem-loops rule out the possibility that the transcripts are processed and then rapidly degraded in the cytoplasm. No processed mRNA accumulates from the $\operatorname{SL}\left(\mathrm{A}^{1,3}\right)$ gene. However, when a second processing signal is placed downstream of the mutant stemloop, then mRNA processed at the mutant stem-loop does accumulate. This result rules out the possibility that the mutant mRNAs are formed and then rapidly degraded.

Additional direct evidence that $3^{\prime}$ processing was impaired comes from the in vitro processing reactions. Histone pre- 
mRNAs containing mutations in the loop or in the stem were not processed well in vitro, although processing was not completely abolished (Fig. 6). Previous studies showed that the stem-loop was not absolutely required for processing in a HeLa cell extract, but that there was a minimal amount of processing of pre-mRNAs which totally lacked a stem-loop (21). The in vitro processing results confirm the results observed in vivo and support the contention that processing is the step which is affected.

The histone $3^{\prime}$ end also plays a role in regulation of the histone mRNA half-life and in localization of the mRNA to polyribosomes. For those genes which expressed detectable mRNA in substantial amounts, SL(CG), SL(UG), and $\operatorname{SL}\left(A^{3}\right)$, the RNAs were all localized on polyribosomes and the amounts decreased when DNA synthesis was inhibited (Fig. 3 and data not shown). Obviously, it is impossible to know the properties of mRNAs containing the other stem-loop mutations which did not express any mature mRNA. Only if these $3^{\prime}$ ends can be created by another mechanism will we be able to study the properties of these mRNAs.

A previous study of the effects of alterations in the stem-loop was carried out by Vasserot et al., using sea urchin histone genes which were injected into sea urchin embryos (33). They observed relatively small (four- to fivefold) effects of altering the stem-loop sequence on the amount of processed sea urchin histone H3 mRNA produced in sea urchin embryos. One of these genes had a reversed stem sequence similar to that of the SL(RS) mutant that we analyzed, and another had all bases in the loop changed. We would not expect these same mutant histone $3^{\prime}$ ends to be processed in transfected mammalian cells. It is likely that the differences between their results (33) and our results are due to differences in the processing system between mammals and sea urchins.

Studies with in vitro processing systems have shown that in some extracts (and with some genes), processing can occur in the absence of the stem-loop sequence with varying efficiency (30), and this could account for the differences observed with similar mutations in the in vitro processing studies of Vasserot et al. (33). The HeLa cell extract used in these experiments and by others (30) requires the stem-loop for efficient processing (Fig. 6), but the stem-loop is not absolutely essential in vitro for processing in extracts from some mouse cells $(30,33)$. A major difference between the experiments with transfected genes and the experiments in cell-free systems is that in the cell there is a competition between degradation of nascent transcripts and the processing reaction, while the unprocessed precursors are stable in the nuclear extract.

Transcripts which are not rapidly processed are immediately degraded in the nucleus. A surprising result was the observation that when an efficient $3^{\prime}$ processing site was placed $3^{\prime}$ of a mutant stem-loop, the amount of mRNA produced from the mutant processing signal was increased. Thus, when either a polyadenylation site or an intact histone $3^{\prime}$ processing signal was placed $3^{\prime}$ of the $\mathrm{A}^{1,3}$ mutant stem-loop, about $10 \%$ of the transcripts which accumulated ended at the mutant histone $3^{\prime}$ end. No transcripts were detectable from the $\operatorname{SL}\left(A^{1,3}\right)$ gene when there was no distal $3^{\prime}$ processing site present (Fig. 4A). This result demonstrates that the presence of the distal processing signal allowed usage of a mutant proximal signal, even though the mutant signal was used inefficiently. The most likely interpretation of this result is that the cell recognizes an unprocessed transcript and rapidly degrades it. The distal processing signal stabilizes the premRNA, allowing more time for the inefficient mutant processing signal to be utilized. A similar result was obtained previously with a natural histone gene with a suboptimal U7 snRNP binding site (15). Placing an efficient $3^{\prime}$ end signal downstream of the gene with the suboptimal U7 binding site stimulated processing at the suboptimal processing site in vivo, although we did not observe any transcripts in steady-state RNA which were processed at the distal site. We attributed the stimulation to stabilization of the pre-mRNA in each case by the distal efficient processing site.

Although processing is the step which is affected by the mutations in the stem-loop, there was not a significant accumulation of unprocessed transcripts in the nucleus. However, using probes which would detect heterogeneous unprocessed transcripts, we did detect transcripts from all of the genes (Fig. 2B; Fig. 4B and C), which were present at a low level. Similar results have been observed in $G_{1}$-phase cells, which transcribe the histone genes but do not process the pre-mRNAs (29). The failure to detect significant amounts of unprocessed precursors suggests that they are very unstable. It seems likely that the cell must have a specific mechanism to recognize an unprocessed transcript and specifically degrade it. Since histone mRNAs are much shorter than most RNA polymerase II transcripts, it seems unlikely that this degradation is a random event, since long transcripts should be potential targets for degradation during the process of transcription. Degradation may require recognition that a potential $3^{\prime}$ processing signal has been transcribed. If the transcript is not processed rapidly, then the transcript is degraded. This wastage phenomenon is important both in determining the level of expression of individual histone genes and in regulating histone mRNA levels during the cell cycle.

Correlation of expression with specificity of the SLBP. We have previously described a protein factor present in nuclei which specifically binds the stem-loop sequence (25). A factor with similar specificity has been detected in extracts prepared from HeLa cells, CHO cells, Xenopus oocytes, and Drosophila cells (34). This factor does not bind to the $\operatorname{SL}\left(\mathrm{A}^{1,3}\right)$ sequence and binds weakly to the $\operatorname{SL}(C G)$ and $\operatorname{SL}\left(A^{3}\right)$ sequences. Here we extended the study of the specificity of this factor to the other mutant stem-loop sequences that we have analyzed in vivo. There is an excellent correlation between the ability of this factor to bind the stem-loop and the expression of the gene (Fig. 7). Since we have shown that the defect in the mutant genes is in RNA processing, it is very possible that the nuclear factor is involved in RNA processing, possibly as part of the hairpin-binding factor $(21,33)$ required in the processing reaction. There is a similar factor present associated with the histone mRNA in the polyribosomes (25), and it is possible that the factor accompanies the mature histone mRNA to the cytoplasm after processing. This factor may be important in protecting the unprocessed transcripts from degradation by binding to the nascent transcript.

\section{ACKNOWLEDGMENTS}

This work was supported by grant GM 29832 from the NIH to W.F.M. U.B. was supported by a grant from the Howard Hughes Medical Institute to Joan A. Steitz.

We thank Therese Yario for assistance with the in vitro processing experiments.

\section{REFERENCES}

1. Birnstiel, M. L., M. Busslinger, and K. Strub. 1985. Transcription termination and 3' processing: the end is in site. Cell 41:349-359.

2. Bond, U. M., T. A. Yario, and J. A. Steitz. 1991. Multiple processing-defective mutations in a mammalian histone premessenger RNA are suppressed by compensatory changes in U7 RNA both in vivo and in vitro. Genes Dev. 5:1709-1722.

3. Chaney, W. G., D. R. Howard, J. W. Pollard, S. Sallustio, and P. Stanley. 1986. High frequency transfection of CHO cells using 
polybrene. Somatic Cell Mol. Genet. 12:237-244.

4. Cotten, M., O. Gick, A. Vasserot, G. Schaffner, and M. L. Birnstiel. 1988. Specific contacts between mammalian U7 snRNA and histone precursor RNA are indispensable for the in vitro RNA processing reaction. EMBO J. 7:801-808.

5. Eckner, R., W. Ellmeier, and M. L. Birnstiel. 1991. Mature mRNA 3 ' end formation stimulates RNA export from the nucleus. EMBO J. 10:3513-3522.

6. Gick, O., A. Krämer, W. Keller, and M. L. Birnstiel. 1986. Generation of histone mRNA $3^{\prime}$ ends by endonucleolytic cleavage of the pre-mRNA in a snRNP-dependent in vitro reaction. EMBO J. 5:1319-1326.

7. Gick, O., A. Krämer, A. Vasserot, and M. L. Birnstiel. 1987. Heat-labile regulatory factor is required for $3^{\prime}$ processing of histone precursor mRNAs. Proc. Natl. Acad. Sci. USA 84:89378940.

8. Graves, R. A., and W. F. Marzluff. 1984. Rapid, reversible alterations in histone gene transcription and histone mRNA levels in mouse myeloma cells. Mol. Cell. Biol. 4:351-357.

9. Graves, R. A., N. B. Pandey, N. Chodchoy, and W. F. Marzluff. 1987. Translation is required for regulation of histone mRNA degradation. Cell 48:615-626.

10. Graves, R. A., S. E. Wellman, I.-M. Chiu, and W. F. Marzluff. 1985. Differential expression of two clusters of mouse histone genes. J. Mol. Biol. 183:179-194.

11. Harris, M. E., R. Böhni, M. H. Schneiderman, L. Ramamurthy, D. Schümperli, and W. F. Marzluff. 1991. Regulation of histone mRNA in the unperturbed cell cycle: evidence suggesting control at two posttranscriptional steps. Mol. Cell. Biol. 11:2416-2424.

12. Hoffmann, I., and M. L. Birnstiel. 1990. Cell cycle-dependent regulation of histone precursor mRNA processing by modulation of U7 snRNA accessibility. Nature (London) 346:665-668.

13. Jackson, R. J., and N. Standart. 1990. Do the poly(A) tail and $3^{\prime}$ untranslated region control mRNA translation. Cell 62:15-24.

14. Levine, B. J., T.-J. Liu, W. F. Marzluff, and A. I. Skoultchi. 1988. Differential expression of individual members of the histone multigene family due to sequences in the $5^{\prime}$ and $3^{\prime}$ regions of the genes. Mol. Cell. Biol. 8:1887-1895.

15. Liu, T.-J., B. J. Levine, A. I. Skoultchi, and W. F. Marzluff. 1989. The efficiency of 3 '-end formation contributes to the relative levels of different histone mRNAs. Mol. Cell. Biol. 9:3499-3508.

16. Lüscher, B., and D. Schümperli. 1987. RNA 3' processing regulates histone mRNA levels in a mammalian cell mutant. A processing factor becomes limiting in G1-arrested cells. EMBO J. 6:1721-1726.

17. Marzluff, W. F. 1992. Histone 3' ends: essential and regulatory functions. Gene Exp. 2:93-97.

18. Marzluff, W. F., and N. B. Pandey. 1988. Multiple levels of regulation of histone mRNA concentrations. Trends Biochem. Sci. 13:49-52.

19. Melin, L., D. Soldati, R. Mital, A. Streit, and D. Schümperli. 1992. Biochemical demonstration of complex formation of histone premRNA with U7 small nuclear ribonucleoprotein and hairpin binding factors. EMBO J. 11:691-697.
20. Milligan, J. F., D. R. Groebe, G. W. Witherell, and O. C. Uhlenbeck. 1987. Oligoribonucleotide synthesis using T7 RNA polymerase and synthetic DNA templates. Nucleic Acids Res. 15:8783-8794.

21. Mowry, K. L., R. Oh, and J. A. Steitz. 1989. Each of the conserved sequence elements flanking the cleavage site of mammalian histone pre-mRNAs has a distinct role in the $3^{\prime}$-end processing reaction. Mol. Cell. Biol. 9:3105-3108.

22. Mowry, K. L., and J. A. Steitz. 1987. Both conserved signals on mammalian histone pre-mRNAs associate with small nuclear ribonucleoproteins during $3^{\prime}$ end formation in vitro. Mol. Cell. Biol. 7:1663-1672.

23. Pandey, N. B., N. Chodchoy, T.-J. Liu, and W. F. Marzluff. 1990. Introns in histone genes alter the distribution of $3^{\prime}$ ends. Nucleic Acids Res. 18:3161-3170.

24. Pandey, N. B., and W. F. Marzluff. 1987. The stem-loop structure at the $3^{\prime}$ end of histone mRNA is necessary and sufficient for regulation of histone mRNA stability. Mol. Cell. Biol. 7:45574559.

25. Pandey, N. B., J.-H. Sun, and W. F. Marzluff. 1991. Different complexes are formed on the $3^{\prime}$ end of histone mRNA in nuclear and polysomal extracts. Nucleic Acids Res. 19:5653-5659.

26. Pilch, D. R., and W. F. Marzluff. 1991. Expression of histone-U1 snRNA chimeric promoters are compatible with histone $3^{\prime}$ end formation. Gene Expression 1:41-53.

27. Roberts, S. B., S. W. Emmons, and G. Childs. 1989. Nucleotide sequences of Caenorhabditis elegans core histone genes. Genes for different histone classes share common flanking sequence elements. J. Mol. Biol. 206:567-577.

28. Sittman, D. B., R. A. Graves, and W. F. Marzluff. 1983. Histone mRNA concentrations are regulated at the level of transcription and mRNA degradation. Proc. Natl. Acad. Sci. USA 80:18491853.

29. Stauber, C., and D. Schümperli. 1988. 3' processing of pre-mRNA plays a major role in proliferation-dependent regulation of histone gene expression. Nucleic Acids Res. 16:9399-9413.

30. Streit, A., T. W. Koning, D. Soldati, L. Melin, and D. Schümperli. 1993. Variable effects of the conserved RNA hairpin element upon $3^{\prime}$ end processing of histone pre-mRNA in vitro. Nucleic Acids Res. 21:1569-1575.

31. Strub, K., and M. L. Birnstiel. 1986. Genetic complementation in the Xenopus oocyte: co-expression of sea urchin histone and U7 RNAs restores $3^{\prime}$ processing of $\mathrm{H} 3$ pre-mRNA in the oocyte. EMBO J. 5:1675-1682.

31a.Sun, J.-H., and W. F. Marzluff. Unpublished data.

32. Sun, J.-H., D. R. Pilch, and W. F. Marzluff. 1992. The histone mRNA 3 ' end is required for localization of histone mRNA to polyribosomes. Nucleic Acids Res. 20:6057-6066.

33. Vasserot, A. P., F. J. Schaufele, and M. L. Birnstiel. 1989. Conserved terminal hairpin sequences of histone mRNA precursors are not involved in duplex formation with the U7 RNA but act as a target site for a distinct processing factor. Proc. Natl. Acad. Sci. USA 86:4345-4349.

34. Williams, A. S., and W. F. Marzluff. Unpublished data. 